UDC 615.072:615.454.142

DOI: $10.15587 / 2519-4852.2020 .215185$

\title{
DETERMINATION OF THE FATTY ACIDS COMPOSITION OF REFINED SUNFLOWER OIL AND POSSIBILITY OF ITS CHANGING DURING STORAGE PERIOD
}

\author{
L. Savchenko, L. Ivanauskas, T. Alekseeva, N. Harna, V. Georgiyants
}

Refined sunflower oil is an auxiliary component of many dosage forms made in pharmacy. For their preparation, pharmacies purchase oils from different manufacturers and have the right to use it throughout the shelf life. However, the question arises of maintaining the stability of the fatty acid composition of the oil because of the influence of various environmental factors. In previous studies, the authors investigated the change in the composition of basic fatty acids (FA) of sunflower oil during heating or long-term storage, but there are no studies of the full FA composition of sunflower oil, as well as an assessment of its dependence on the period of the oil using.

The aim. Detailed study of the FA composition of refined sunflower oil from different manufacturers, assessment of the effect of the shelf life of the oil on its FA composition and its compliance with the requirements of the European Pharmacopoeia (EP).

Materials and methods. The determination of the FA composition of seven samples of refined sunflower oil was carried out by gas chromatography with a flame ionization detector using the Rt-2560 column $(100 \mathrm{~m} \times 0.25 \mathrm{~mm} \times 0.20 \mu \mathrm{m})$.

Results. The analysis of seven samples of refined sunflower oil showed the presence of 24 FA in most of them. Polyunsaturated FA predominate among them with a percentage of 52.45-60.86\%. The value of the fatty acids percentage in each groups (saturated, mono- and polyunsaturated fatty acids) are quite similar regardless of the oil shelf life at the time of the research. All test samples, except one, by the percentage content of the main FA correspond to EP requirements. The results of the quantitative content of the main FA of sunflower oil determining (palmitic, stearic, oleic, and linoleic) also indicate a similar FA composition of the studied samples.

Conclusions. The studied samples of sunflower oil refined in terms of the content of basic FAs meet the requirements of the EP. The obtained results indicate the high stability of the oil and the absence of a significant effect of the storage period on the FA composition

Keywords: refined sunflower oil, fatty acid composition, quality

Copyright (C) 2020, L. Savchenko, L. Ivanauskas, T. Alekseeva, N. Harna, V. Georgiyants. This is an open access article under the CC BY license (http://creativecommons.org/licenses/by/4.0).

\section{Introduction}

Sunflower oil is an auxiliary ingredient in compounding medicines. Most often it is part of ointments, creams [1] and suspensions. In many suspensions for the treatment of the oral mucosa, sunflower oil is the basis of the dosage forms, where it is combined with various pharmacologically active ingredients. Despite its nature, due to its rich FA composition, sunflower oil has a beneficial effect on the skin and mucous membranes, has wound-healing and anti-inflammatory properties [1].

According to the monograph "Non-sterile compounding medicines" requirements [2] excipients should meet the requirements of the relevant monographs of the State Pharmacopoeia of Ukraine (SPhU). In case of their absence, they should correspond to the general monograph "Substances for pharmaceutical use" or other current regulations. Thus, the quality of sunflower oil should be checked for compliance with modern requirements.

One of the issues of the possibility of using refined sunflower oil in the manufacture of compounding medicines in pharmacies is stability of its FA composition preservation throughout the whole shelf life. Pharmacies are using oil from different domestic manufactur- ers for compounding medicines preparation. Pharmacies has the right to purchase and use them during the entire shelf life (the shelf life of all tested oils samples specified by the manufacturer in the certificate of analysis is 2 years). However, due to the content of unsaturated FA, it is possible that the quality of the oil may deteriorate due to the increasing of peroxide value or other values as a result of oxidation or other damage due to the environmental factors.

$\mathrm{SPhU}$ does not contain any requirements to the refined sunflower oil quality. 10.0 edition of EP contains monograph "Sunflower oil, refined" [3]. It was also part of the USSR SPh IX edition (Oleum Helianthi (Sunflower oil)) [4]. Evaluation of the certificates of analysis of the majority of the studied samples of sunflower oil testifies that the most manufacturers are determine their quality indicators according to the requirements of the SStU 4492: 2017 "Sunflower oil. Technical conditions" [5]. It contains the widest set of the oil quality indicators.

The requirements of all three documents for the quality of refined sunflower oil are slightly different. The main difference of the EP 10.0 and SStU 4492: 2017 "Sunflower oil. Technical conditions" requirements to 
the sunflower oil is the regulation of its FA composition. The last document regulates the percentage content of more FA (Table 1). The EP has requirements only for four FA compositions.

Table 1

Requirements to the FA composition of refined sunflower oil

\begin{tabular}{|l|c|c|}
\hline \multirow{2}{*}{ Name of FA } & $\begin{array}{c}\text { Percentage content (\% to the amount } \\
\text { of total FA content) }\end{array}$ \\
\cline { 2 - 3 } & $\begin{array}{c}\text { EP mono- } \\
\text { graph }\end{array}$ & SSt $U$ 4492:2017 \\
\hline Myristic & & not more than 0.2 \\
\hline Palmitic & 4.0 to 9.0 & 5.0 to 7.6 \\
\hline Palmitoleic & & not more than 0.3 \\
\hline Stearic & 1.0 to 7.0 & 2.7 to 6.5 \\
\hline Oleic & 14.0 to 40.0 & $» 14.0 » 39.4$ \\
\hline Linoleic & 48.0 to 74.0 & » $48.3 » 74.0$ \\
\hline Linolenic & & not more than 0.3 \\
\hline Arachidic & & 0.1 to 0.5 \\
\hline Eicosenoic & & not more than 0.3 \\
\hline Behenic & & 0.3 to 1.5 \\
\hline Lignoceric & & not more than 0.5 \\
\hline
\end{tabular}

In some previous studies, the analysis of changes in the FA composition of sunflower oil after heating in the presence of natural antioxidants [6], in domestic conditions [7] and at different temperatures [8, 9] was done. However, they describe and analyze changes in the content of only main FA without determining the degree of influence of different oil storage times on its full FA composition. The subject of the analysis in these researches not always is refined sunflower oil.

Thus, it is necessary to study the fullest FA composition of refined sunflower oils from different manufacturers, which are used for the manufacture of medicines in pharmacies. The obtained results will allow analyzing the dependence of the percentage content of FA on the period of oil use.

The aim of the research was to study FA composition of different sunflower oils obtained from different manufacturers, checking its dependence on the shelf life of oil and assessing compliance with the requirements of the EP.

\section{Planning (methodology) of research}

To achieve this aim and get answers to all questions, the design of the experiment was done (Fig. 1).

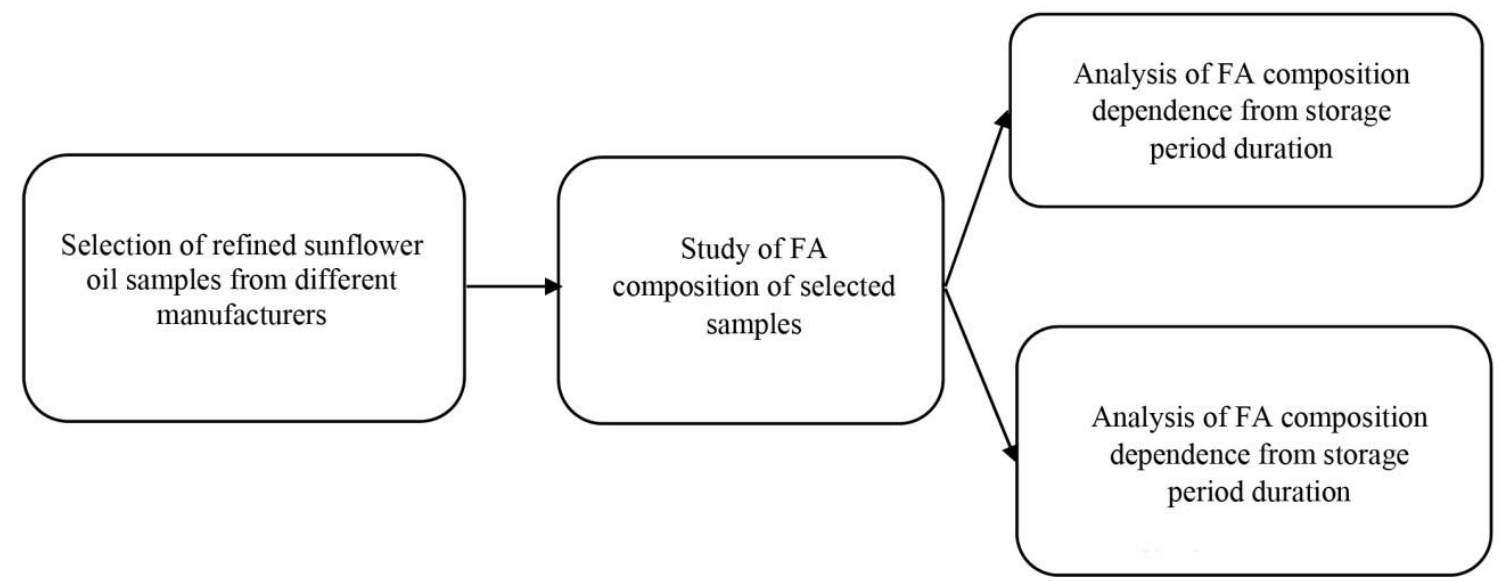

Fig. 1. Design of the experiment

\section{Materials and methods}

Seven samples of refined sunflower oil were selected for the analysis. They were used for the compounding medicines preparation in different pharmacies:

- sample No. 1, PJSC «Dnipropetrovsk oil extraction plant», produced in Ukraine, date of manufacture 01.2018;

- sample No. 2, TM «Chumak» TM «Zolota», produced in Ukraine, date of manufacture 06.2017;

- sample No. 3, TM «Chumak» TM «Zolota», produced in Ukraine, date of manufacture 01.2019;

- sample No. 4, PJSC with II «DOEZ», produced in Ukraine, date of manufacture 04.2017;

- sample No. 5, «Tsarska oliya», produced in Ukraine, date of manufacture 12.2017;

- sample No. 6, «Shchedryy dar», produced in Ukraine, date of manufacture 04.2018;
- sample No. 7, «Shchebpak», produced in Ukraine, date of manufacture 03.2018.

Six samples were analyzed in June, 2019. Sample No. 3 was analyzed in March, 2020.

The analysis was performed on a gas chromatograph GC-2010 Plus Shimadzu with flame ionization detector and autosampler AOC-20i + s. For determining the content of the maximum amount of FA capillary column Rt-2560 coated with biscianopropylpolysiloxane $(100 \mathrm{M} \times 0.25 \mathrm{MM} \times 0.20 \mu \mathrm{M})$ produced by Restek Corporation, USA, was used. For the formation of FA methyl esters (FAME) boron-trifluoride reagent $(\sim 10 \%)$ series BCBZ5554 produced by Sigma-Aldrich, USA was used. Supelco 37 Component FAME Mix $(1 \times 1 \mathrm{ml}$, different concentrations in dichloromethane) series XA16739V produced by the same manufacturer was used as a standard. 
GC-FID method: the injector temperature was $230{ }^{\circ} \mathrm{C}$, the detector temperature was $250{ }^{\circ} \mathrm{C}$. The temperature program for the column was: the initial temperature $100{ }^{\circ} \mathrm{C}$, hold at $100{ }^{\circ} \mathrm{C}$ for $5 \mathrm{~min}$, increase by $3{ }^{\circ} \mathrm{C} / \mathrm{min}$ to $240{ }^{\circ} \mathrm{C}$ and then hold at this temperature for $20 \mathrm{~min}$. Injection volume was $1.0 \mu \mathrm{l}$, injection mode was split (split ratio 1:100), carrier gas - helium.

Sample preparation: $0.050 \mathrm{~g}$ of the oil sample was weighted into the $10 \mathrm{ml}$ vial. $0.25 \mathrm{ml}$ of the potassium hydroxide $60 \mathrm{~g} / \mathrm{l}$ solution in methanol and $1 \mathrm{ml}$ of the boron-trifluoride solution $(\sim 10 \%)$ were added to the oil sample. The vial was tightly closed, shaken and left on a glycerin bath with a temperature of $100{ }^{\circ} \mathrm{C}$ for 3 hours. $1 \mathrm{ml}$ of water and $1 \mathrm{ml}$ of hexane were added after complete cooling of the vial. Vial was closed and shaken for 1 minute. Then it was allowed to settle until the layers are completely separated. A hexane layer was used for the analysis.

FAME were identified by comparing their retention times with the retention times of the standard solution components.

The percentage of each FA was defined as the ratio of the area of the corresponding peak to the sum of the peak areas of all identified FAs. The sum consisted of the areas of all peaks except the solvent peaks. The peak areas of all identified FAME were taken into account, regardless of the peak area.

\section{Results}

In most studied samples of refined sunflower oil, 24 FAs were identified (Table 2). An example of a chromatogram of a solution of sunflower oil is shown in Fig. 2 (the result of the analysis of the sample No. 1). The summary table (Table 2) includes FAs, the percentage content of which was higher than $0.05 \%$. All results shown in the table are the average result of six measurements (three sample of each oil, two parallel analyzes of each of them). 13 saturated, 6 monounsaturated and 5 polyunsaturated FAs were identified in most of the studied samples.

In addition to the saturated FA listed in the Table 2 , caproic $(0.003-0.049 \%)$, caprylic $(0.005-0.011 \%)$, capric $(0.001-0.003 \%)$, lauric $(0.001-0.002 \%)$, pentadecanoic (0.008-0.016\%), heneicosanoic (0.001-0.010\%) acids were identified in all samples.

Among the monounsaturated FAs cis-10heptadecenoic $(0.017-0.024 \%)$, erucic $(0.002-0.006 \%)$ and nervonic (0.001-0.008\%) acids were found in all samples.

In all samples of sunflower oil polyunsaturated cis-8,11,14-eicosatrienoic $(0.03-0.07 \%)$ and cis5,8,11,14-eicosatetraenoic (0.011-0.042\%) acids were identified. Myristoleic $(0.017 \%)$ and cis-13,16docosadienoic $(0.013 \%)$ acids were identified only in the third sample.

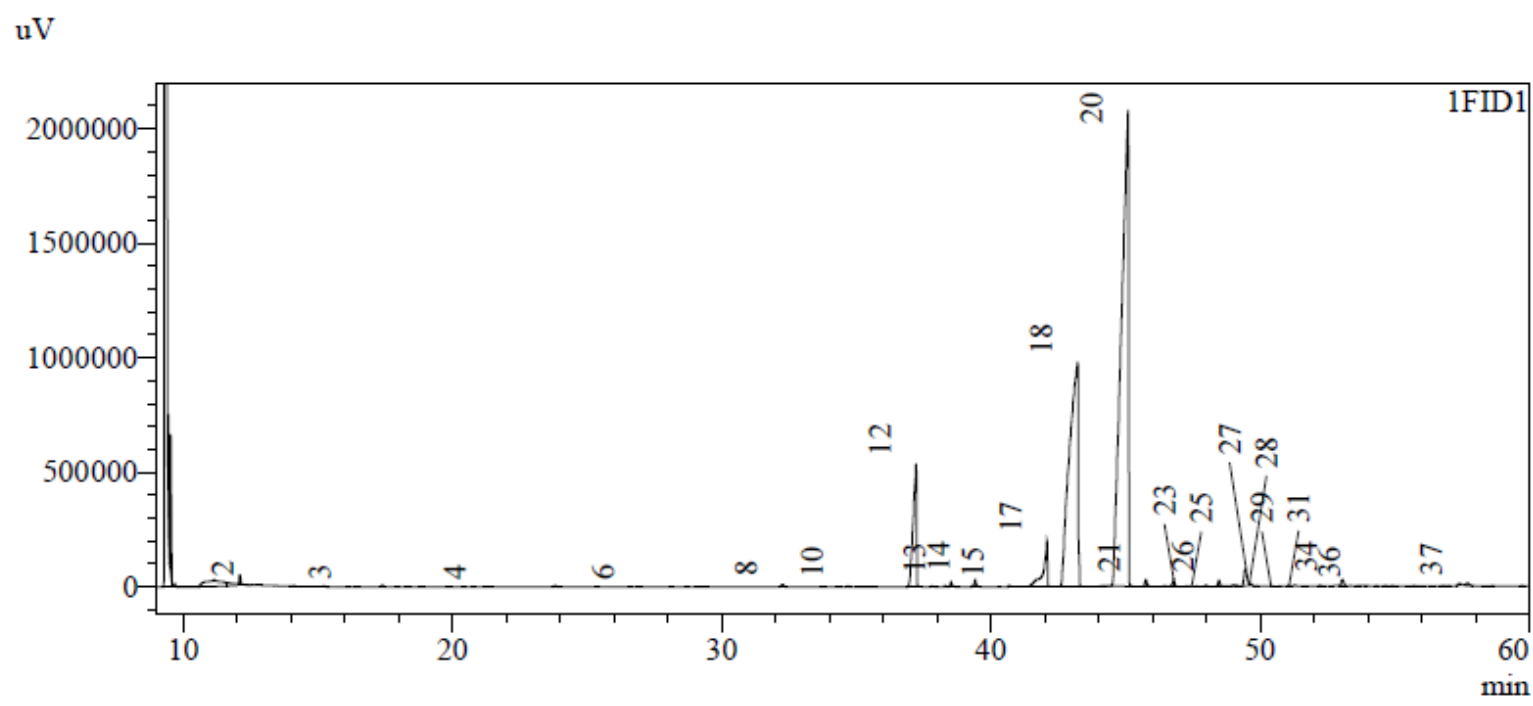

Fig. 2. Chromatogram of the sunflower oil solution (sample No. 1):

2 - methyl hexanoate; 3 - methyl octanoate;

4 - methyl decanoate; 6 - methyl laurate; 8 - methyl myristate; 10 - methyl pentadecanoate; 12 - methyl palmitate;

13 - methyl palmitoleate; 14 - methyl heptadecanoate; 15 - cis-10-heptadecenoic acid methyl ester; 16 - methyl stearate; 18 - cis-9-oleic acid methyl ester; 20 - methyl linoleate; 21 - methyl arachidate; 23 - methyl eicosenoate;

25 - methyl heneicosanoate; 26 - cis-11,14-eicosadienoic acid methyl ester;

27 - methyl behenate; 28 - cis-8,11,14-eicosatrienoic acid methyl ester; 29 - methyl erucate; 31 - methyl cis-5,8,11,14-eicosatetraenoic acid methyl ester;

34 - methyl lignocerate; 36 - methyl nervonate; 37 - cis-4,7,10,13,16,19-docosahexaenoic acid methyl ester 
Table 2

Results of the FA content determination of the sunflower oil refined samples

\begin{tabular}{|c|c|c|c|c|c|c|c|c|}
\hline \multirow{2}{*}{ Fatty acids (\% of total FA) } & \multicolumn{6}{|c|}{ Sample number } & \multirow{2}{*}{$\begin{array}{l}\text { Average } \\
\text { value }\end{array}$} & \multirow{2}{*}{ No. 3} \\
\hline & No. 1 & No. 2 & No. 4 & No. 5 & No. 6 & No. 7 & & \\
\hline \multicolumn{9}{|c|}{ Saturated fatty acids } \\
\hline Myristic (14:0) & 0.08 & 0.08 & 0.08 & 0.08 & 0.08 & 0.08 & 0.08 & 0.04 \\
\hline Palmitic (16:0) & 6.94 & 6.89 & 6.84 & 6.66 & 6.73 & 6.33 & 6.73 & 3.87 \\
\hline Margaric (17:0) & 0.20 & 0.26 & 0.20 & 0.06 & 0.27 & 0.17 & 0.19 & 0.45 \\
\hline Stearic (18:0) & 3.07 & 3.31 & 3.18 & 3.50 & 2.95 & 3.12 & 3.19 & 2.07 \\
\hline Arachidic (20:0) & 0.24 & 0.25 & 0.24 & 0.23 & 0.21 & 0.22 & 0.23 & 0.14 \\
\hline Behenic (22:0) & 0.86 & 0.86 & 0.79 & 0.64 & 0.71 & 0.70 & 0.76 & 0.50 \\
\hline Lignoceric (24:0) & 0.27 & 0.28 & 0.24 & 0.19 & 0.22 & 0.23 & 0.24 & 0.16 \\
\hline Total saturated FA (TSFA) & 11.66 & 11.93 & 11.57 & 11.36 & 11.17 & 10.85 & 11.42 & 6.73 \\
\hline \multicolumn{9}{|c|}{ Monounsaturated fatty acids } \\
\hline Palmitoleic (16:1) & 0.13 & 0.12 & 0.13 & 0.10 & 0.12 & 0.11 & 0.12 & 0.05 \\
\hline Cis-9-oleic acid (18:1) & 32.26 & 26.68 & 31.88 & 28.14 & 35.87 & 32.86 & 31.28 & 16.47 \\
\hline Eicosenoic $(20: 1)$ & 0.24 & 0.23 & 0.24 & 0.25 & 0.25 & 0.21 & 0.24 & 0.12 \\
\hline Total momounsaturated FA (TMUFA) & 32.63 & 27.03 & 32.25 & 28.49 & 36.24 & 33.18 & 31.64 & 16.64 \\
\hline \multicolumn{9}{|c|}{ Polyunsaturated fatty acids } \\
\hline Linoleic (18:2) & 55.26 & 60.53 & 55.67 & 59.97 & 52.12 & 55.60 & 56.53 & 30.07 \\
\hline Cis-11,14-eicosadienoic acid (20:2) & 0.21 & 0.19 & 0.12 & 0.07 & 0.13 & 0.13 & 0.14 & 0.11 \\
\hline $\begin{array}{l}\text { Cis-4,7,10,13,16,19-docosahexaenoic acid } \\
(22: 6)\end{array}$ & 0.10 & 0.14 & 0.23 & 0.04 & 0.20 & 0.10 & 0.14 & 0.21 \\
\hline Total polyunsaturated FA (TPUFA) & 55.57 & 60.86 & 56.02 & 60.08 & 52.45 & 55.83 & 56.81 & 30.39 \\
\hline Total unsaturated FA (TUFA) & 88.20 & 87.89 & 88.27 & 88.57 & 88.69 & 89.01 & 88.45 & 47.03 \\
\hline TUFA/TSFA* & 7.56 & 7.37 & 7.63 & 7.80 & 7.94 & 8.20 & 7.75 & 6.99 \\
\hline
\end{tabular}

Note: $*$ TUFA/TSFA - values of ratio total unsaturated/total saturated fatty acids

\section{Discussion}

The analysis of the obtained results showing the close FA composition of all samples of refined sunflower oil, except for the sample № 3. If we take into account the requirements of the EP to the percentage content of basic FA in sunflower oil, the content of palmitic and linoleic acids in it is lower than the established requirements. The content of stearic and oleic acids meets the monograph requirements, but they close to the lower limit define it. Therefore, a hypothesis about the need to exclude this sample from further analysis was put forward.

To confirm the hypothesis, the homogeneity of the values of the main four FAs percentage content according to the requirements of subsection 5.3.N.1. Statistical analysis of the results of a chemical experiment [10] by the formulas below (1) was assessed.

$$
R=\left\lfloor x_{1}-x_{n}\right\rfloor ; Q_{1}=\frac{\left\lfloor x_{1}-x_{2}\right\rfloor}{R} .
$$

The obtained results (Table 3) indicate that the hypothesis that

- the value of the percentage content of palmitic $\left(\mathrm{x}_{1}=3.87 \%\right)$ and linoleic $\left(\mathrm{x}_{2}=30.07 \%\right)$ acids in the sample No. 3 should be excluded from the set of measurement results as burdened with a gross error can be accepted with a confidence level of both $95 \%$ and $99 \%$;

- the value of the percentage content of stearic $\left(\mathrm{x}_{3}=2.07 \%\right)$ and oleic $\left(\mathrm{x}_{4}=16.47 \%\right)$ acids in the sample No. 3 should be excluded from the set of measurement results as burdened with a gross error can be accepted with a confidence level of $95 \%$ and rejected with a confidence level of $99 \%$.

Table 3

The results of checking the series of values of the percentage content of FA for homogeneity

\begin{tabular}{|c|c|c|c|c|}
\hline$F A$ & $R$ & $Q_{1}$ & Criterion & Conclusion \\
\hline Palmitic & 3.07 & 0.80 & \multirow{4}{*}{$\begin{array}{l}Q(7 ; 95 \%)=0.51 \\
Q(7 ; 99 \%)=0.64\end{array}$} & $0.51<0.80 ; 0.64<0.80$ \\
\hline Stearic & 1.43 & 0.62 & & $0.51<0.62 ; 0.64>0.62$ \\
\hline Oleic & 19.4 & 0.53 & & $0.51<0.53 ; 0.64>0.53$ \\
\hline Linoleic & 30.46 & 0.72 & & $0.51<0.72 ; 0.64<0.72$ \\
\hline
\end{tabular}

Thus, the results of statistical analysis confirm the need to exclude sample № 3 from the set of results.

Despite the large number of saturated FAs in sunflower oil samples, their total percentage content is the lowest and varies between 10.85-11.93\% (Table 2). Palmitic and stearic acids are characterized by the highest content among saturated FA.
The second place by percentage content is occupied by monounsaturated FAs (27.03-36.24\%). Oleic acid is characterized by the highest content among them.

Slightly more than half of the total amount of FA in sunflower oil samples are polyunsaturated FA with a percentage content of $52.45-60.86 \%$. The main polyunsaturated acid is linoleic acid. 
It should be noted that the percentage of each individual FA is characterized by the fairly close values and a small scatter relative to the average value. The value of the ratio of total unsaturated FA content to total saturated FA content was calculated. It varies in the range of 7.37-8.20. Its average value was 7.75.

Evaluation of the FA composition dependence from the shelf life of the oil indicates its high stability. Even samples No. 2 and No. 4, which have expired at the time of analysis meet the requirements of the EP by the percentage content of the basic FAs. The percentage of particular FAs in these samples does not differ significantly from other samples with a shorter shelf life at the time of analysis.

The quantitative content of basic FAs in sunflower oil samples, the percentage content of which is regulated by the EP requirements, was also determined (Fig. 3).

The quantitative content of the main FA in almost all samples of sunflower oil is comparable and has no significant differences. The quantitative content of FA in the sample No. 3 differs significantly, as expected.

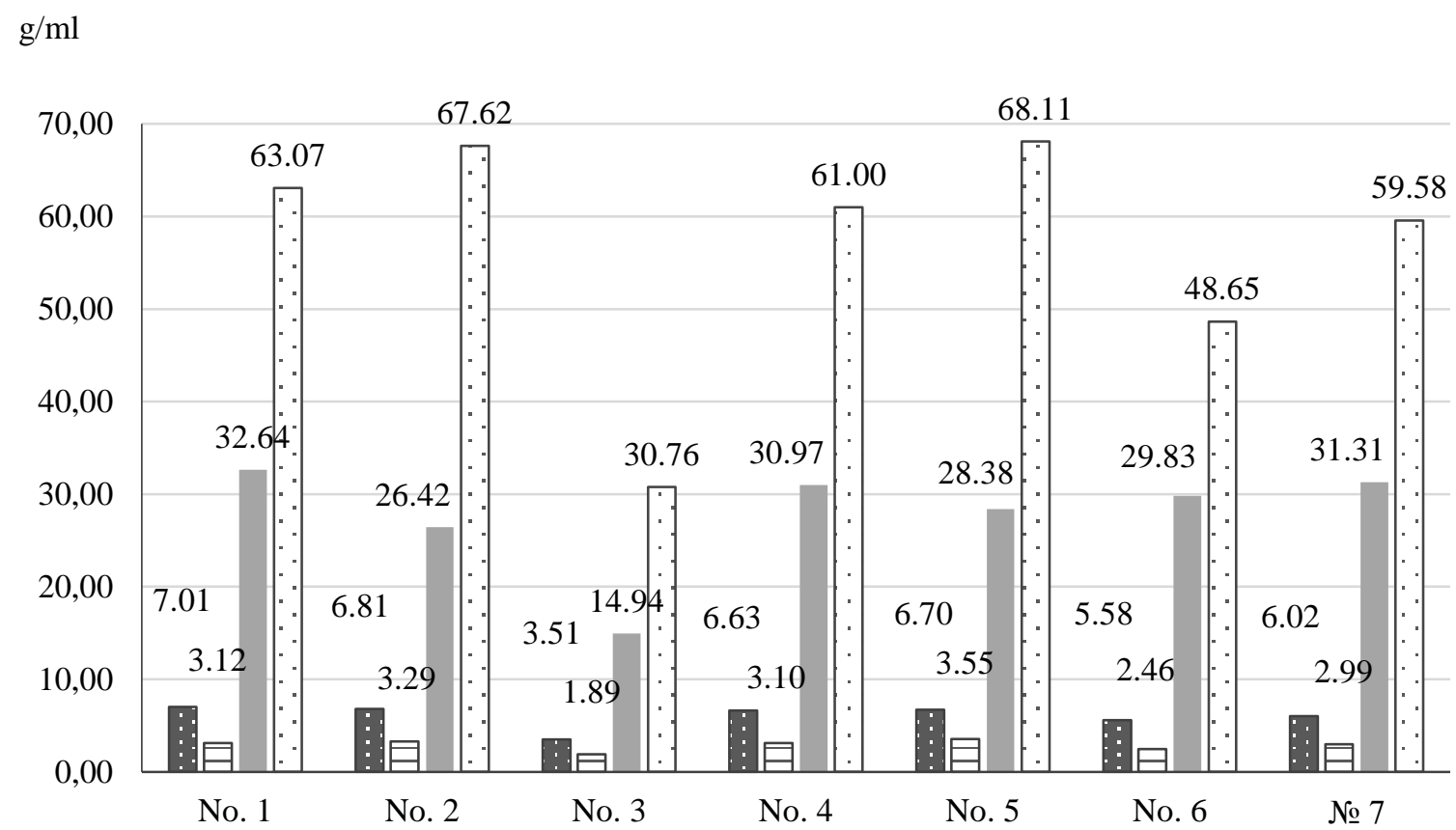

$\square$ Palmitic acid $\quad \square$ Stearic acid $\quad \square$ Oleic acid $\square$ Linoleic acid

Fig. 3. Quantitative content of the main FA in sunflower oil samples

Study limitations. Of course, this analysis does not cover all Ukrainian manufacturers of refined sunflower oil. Pharmacies can purchase oil at other enterprises. However, the homogeneity of the obtained results and their proximity allows confirming the reliability of the obtained general conclusions.

Prospects for further research. The obtained results of the percentage content of the main FA in the samples of sunflower oil refined can be used in further studies for the introduction of a monograph on sunflower oil in SPhU.

The conclusion that most samples of sunflower oil meet the requirements of the EP indicates the possibility of adapting its standards in Ukraine for Ukrainian sunflower oils.

\section{Conclusions}

The study of the complete FA composition of seven samples of refined sunflower oil from different manufacturers was carried out using the GC method.
24 FA were identified in most samples. The main group among them were polyunsaturated FA.

Only one sample among tested does not meet the requirements of the EP for the percentage content of basic FA. A significant difference was proved by statistical analysis of the obtained values.

FA composition of the samples indicates their high stability. The percentage of FA in them is quite close and does not depend on the shelf life of the oil.

\section{Conflict of interest}

The authors declare that they have no conflicts of interest.

\section{Funding}

Research was funded by the Ministry of Health of Ukraine at the expense of the state budget in the theme "Development of monographs of the State Pharmacopoeia of Ukraine for compounding medicines" framework (state registration number: 0120U102430). 


\section{References}

1. Guidoni, M., de Christo Scherer, M. M., Figueira, M. M., Schmitt, E. F. P., de Almeida, L. C., Scherer, R. et. al. (2019). Fatty acid composition of vegetable oil blend and in vitro effects of pharmacotherapeutical skin care applications. Brazilian Journal of Medical and Biological Research, 52 (2). doi: http://doi.org/10.1590/1414-431x20188209

2. Derzhavna Farmakopeia Ukrainy. Vol. 3 (2014). Kharkiv: Derzhavne pidpryiemstvo «Ukrainskyi naukovyi farmakopeinyi tsentr yakosti likarskykh zasobiv», 732 .

3. Sunflower oil, refined: in European Pharmacopoeia (2020). Strasbourg: European Directorate for the Quality of Medicines, 3948.

4. Gosudarstvennaia Farmakopeia SSSR (1961). Moscow: Gosudarstvennoe izdatelstvo meditsinskoi literatury MEDGIZ, 914.

5. DSTU 4492:2017. Oliia soniashnykova. Tekhnichni umovy (2018). Kyiv: DP “UkrNDNTs", 25.

6. Kowalski, R. (2007). GC analysis of changes in the fatty acid composition of Sunflower and Olive oils heated with quercetin, caffeic acid, protocatechuic acid, and butylated hydroxyanisole. Acta Chromatographica, 18, 15-23.

7. Porto, B. L. S., Mendes, T. O., Franco, D. F., Martini, W. S., Bell, M. J. V., Oliveira, M. A. L. (2016). Chemical monitoring of canola, corn, olive, soybean and sunflower oils after thermal treatment at conventional temperatures in domestic stoves. Revista do Instituto Adolfo Lutz, 75 (1694), 11.

8. Kowalski, R., Kowalska, G., Pankiewicz, U., Sujka, M., Kałwa, K. (2017). GC analysis in evaluation of changes in fatty acids content of selected fats during storage and heating. Bulgarian Chemical Communications, 49 (4), 928-935.

9. Cihelkova, K., Zarubova, M., Hradkova, I., Filip, V., Šmidrkal, J. (2009). Changes of Sunflower Oil polyenoic fatty acids under high temperatures. Czech Journal of Food Sciences, 27, S13-S16. doi: http://doi.org/10.17221/918-cjfs

10. Derzhavna Farmakopeia Ukrainy. Vol. 1 (2015). Kharkiv: Derzhavne pidpryiemstvo «Ukrainskyi naukovyi farmakopeinyi tsentr yakosti likarskykh zasobiv», 1128.

Received date 11.08.2020

Accepted date 23.09.2020

Published date 30.10.2020

Lesia Savchenko, PhD, Associate Professor, Department of Quality, Standardization and Certification of Medicines, National University of Pharmacy, Pushkinska str., 53, Kharkiv, Ukraine, 61002

E-mail: savchenkolesia@gmail.com

Liudas Ivanauskas, Doctor of Biomedical Sciences, Professor, Department of Analytical and Toxicological Chemistry, Lithuanian University of Health Sciences, Mickeviciaus str., 9, Kaunas, Lithuania, 44307

E-mail: Liudas.Ivanauskas@1smuni.lt

Tetyana Alekseeva, PhD, Associate Professor, Department Pharmaceutical Chemistry, National University of Pharmacy, Pushkinska str., 53, Kharkiv, Ukraine, 61002

E-mail: tetyanavyktorivna@gmail.com

Nataliya Harna, PhD, Associate Professor, Department Pharmaceutical Chemistry, National University of Pharmacy, Pushkinska str., 53, Kharkiv, Ukraine, 61002

E-mail: GarnayaN@ukr.net

Victoriya Georgiyants, Doctor of Pharmaceutical Sciences, Professor, Department of Pharmaceutical Chemistry, National University of Pharmacy, Pushkinska str., 53, Kharkiv, Ukraine, 61002

E-mail: vgeor@ukr.net 